\title{
Long noncoding LINC00238 restrains Hepatocellular Carcinoma Malignant Phenotype via Sponging miR-522
}

Honggang Qian ( $\sim$ qianhg@bjcancer.org )

Beijing Hospital https://orcid.org/0000-0003-2240-5546

Qiong Wu

Tsinghua University

Jian-Hui Wu

Beijing University

Xiu-Yun Tian

Beijing University

Wei Xu

Beijing University

Chun-Yi Hao

Beijing University

Research article

Keywords: IncRNA, LINC00238, miR-522, SFRP2, DKK1, Hepatocellular Carcinoma

Posted Date: May 18th, 2021

DOl: https://doi.org/10.21203/rs.3.rs-531043/v1

License: (9) (i) This work is licensed under a Creative Commons Attribution 4.0 International License.

Read Full License 


\section{Abstract}

Background: Long noncoding RNA (IncRNA) Can regulates tumor malignant phenotype either as a tumor suppressor or an oncogene. In hepatocellular carcinoma (HCC), the clinical significance and underlying mechanism of LINC00238 function remain undefined.

Methods: Down-regulated expression levels of noncoding RNAs were screened from TCGA LIHC dataset through GEPIA software. The expression of RNAs were determined by qRT-PCR. Molecular clone was performed to over-expression and knockdown of LINC00238 expression. The levels of proteins were evaluated via Western blot. The cell viability, clone formation and migration ability were assessed by CCK8, plate clone formation and Transwell assays. RNA pull down and Luciferase reporter assays were applied to detect the interplays between LINC00992 and miR-3935.

Results: LINC00238 was identified as a significant downregulated both in TCGA and in our cohort, and its low expression was significantly correlated with bigger tumor size, early recurrence and poor survival of patients with HCC after surgery. Through the results of gain and loss of function experiments, LINC00238 was confirmed as a tumor suppressor》 which could decrease not only cell viability, migration and invasion in vitro but also tumorigenesis and tumor metastasis in vivo. Mechanistically, RNA pull-down showed that LINC00238 sponged mir-522, and then, released the inhibition effects on two downstream targets, SFRP2 and DKK1.

Conclusions: We identified LINC00238 as a tumor suppressor by sponging miR-522 followed by release silencing of downstream targets, suggesting that LINC00238 has a key role in restraining the malignant phenotype of HCC cells and providing a novel perspective on IncRNAs in HCC progression.

\section{Background}

Globally, liver cancer is the fifth frequent fatal malignancy in United States[1],but ranks second in China[2] due to the high risk of the hepatitis B virus (HBV) or hepatitis C virus (HCV) infection, fatty liver disease, and alcohol-related cirrhosis et.al. About $5-15 \%$ of patients are suitable for surgical removal only for early-stage patients [3]. The prognosis for unresectable stage liver cancer is very poor with only about 620 months for their median survival time, and less than $5 \%$ for their 5 -year survival[4]. Therefore, discovering prognostic or therapeutic biomarkers is still urgently needed for hepatocellular carcinoma patients.

IncRNAs are defined as non-coding RNAs longer than 200 nucleotides. Although IncRNAs undergo similar processing as mRNAs such as splicing, capping, polyadenylation and editing, they lack significant open reading frames. Increasing evidence implicates that IncRNAs are participated in every aspect in the life cycle of a gene, including transcription, splicing, RNA decay and translation. Cytoplasmic LncRNAs can regulate gene expression via diverse mechanisms, either by sponging miRNA or altering mRNA stability. 
To date, a total of 74 deregulation of HCC-associated IncRNAs have been reported, with 52 upregulated IncRNAs exhibiting oncogenic properties and 22 downregulated IncRNAs having tumor-suppressive properties [5]. Therefore, these insights reveal that novel IncRNAs might be as potential biomarkers and enable the design of precision therapy for HCC. Previously, it has reported that HBV infection inhibited the expression of LINC00238, which is significantly down-regulated in HBV positive liver tissues, HBV expression cell line and HBV transient expression cells [6]. Furthermore, overexpression of LINC00238 can suppress HBV replication [6]. To our knowledge, chronic HBV infection is a major risk factor for hepatocellular carcinoma, and notably, in China, HBV-related HCC accounts for about $85 \%$ of HCC cases due to the high prevalence of HBV infection. However, the role of LINC00238 in HCC progression is still unclear.

In this investigation, we detected the expression profile of LINC00238 in HCC, and identified it as a tumor suppressor. Mechanistically, LINC00238 acts as a molecular sponge to adsorb miR-522, resulting in its relieving suppression of two downstream targets genes, SFRP2 and DKK1. We therefore describe the functions of a novel IncRNA that regulates malignant phenotype of HCC.

\section{Methods}

\section{GEPIA analysis of TCGA and GEO data}

GEPIA (http://gepia.cancer-pku.cn) was used to analyze the aberrant expression lincRNAs by differential expression analysis of liver hepatocellular carcinoma ( $\mathrm{LIHC}$ ). We selected the under-expressed lincRNAs among the differential geneswith $|\log 2 \mathrm{FC}|$ Cutoff $=1$ and q-value Cutoff $=0.01$. Next, survival analysis was performed for these under-expressed lincRNAs to obtain lincRNAs associated with overall survival of patients after surgery by Median expression level of each lincRNA in LIHC $(P<0.1)$.

\section{Clinical specimens}

Primary HCC specimens ( $\mathrm{n}=90$ cases) and matched adjacent normal tissues) were obtained from the Biobank of Peking University Cancer Hospital from patients who underwent surgery from 2003 to 2010. The following inclusion/exclusion criteria were applied for patients: (a) with pathological diagnosis of HCC; (b) with complete follow-up information; (c) without any preoperative chemotherapy. Before collection of specimens, written and informed consent was obtained from all patients.

\section{Cell lines and cell culture}

The human normal hepatic L02 cells and HCC cells, including HepG2, SMMC-7721, PLC/PRF/5, BEL-7402 and Huh7 were purchased from the Chinese Academy of Medical Sciences \& Peking Union Medical College (Beijing, China). Cells were cultured in RPMI 1640 with $10 \%$ fetal bovine serum (FBS), $100 \mathrm{U} / \mathrm{mL}$ penicillin, and $100 \mathrm{mg} / \mathrm{mL}$ streptomycin in a $5 \% \mathrm{CO}_{2}$ humidified incubator at $37^{\circ} \mathrm{C}$.

\section{RNA extraction andreal time q-PCR analysis}


Total RNA was isolated from tissues or cells by a miRNeasy mini kit (Qiagen). Separation and purification of cytoplasmic and nuclear RNA from HepG2 and Huh7 cells was performed using a specific kit (NorgenBiotek Corp).First strand cDNA was synthesized from $5 \mu \mathrm{g}$ of RNA using random primers and Moloney murine leukemia virus reverse transcriptase (M-MLV RT) (Invitrogen). For miRNA detection, 100ng RNA was firstly added with polyA tails by polyA polymerase (NEB) and then synthesis of cDNA by OligodT-Adaptor and M-MLV RT. Real-time quantitative PCR (q-PCR) was performed using SYBR Green PCR Master Mix (Applied Biosystems) on an ABI 7500 System (Applied Biosystems). The gene expression level was calculated by the $2^{-\Delta \mathrm{Ct}}$ method, where $\Delta \mathrm{Ct}=\mathrm{Ct}$ (gene)-Ct (GAPDH). For miRNA expression, we used $\mathrm{U} 6$ as the internal reference gene. Q-PCR data are represented as the mean \pm S.D. from three independent triplicate experiments.

\section{Plasmid construction and cell transfection}

LINC00238 (NR_024338.3) were subcloned into a pcDNA3.1 (+) expression vector. Plasmids were transfected into cells, and selected by $500 \mathrm{mg} / \mathrm{ml} \mathrm{G} 418$ solution for 1 week to obtain stable overexpressing. The lentivirus RNAi shuttle vector containing the sequence for the short-hairpin RNA (shRNA) in the LINC00238 were transfected into HEK 293FT cells together with the lentiviral helper plasmids PLP1, PLP2 and pLP/VSVG to generate lentiviruses. Lentiviruses infected cancer cells were screened with $1 \mu \mathrm{g} / \mathrm{ml}$ Blastcidine S. All plasmids were confirmed by sequencing.

\section{Cell viability and plate colony formation assay}

A total of $1 \times 10^{3}$ cells/well seeded into 96 -well plates. Cell viability was evaluated by Cell Counting Kit-8 (CCK-8; Dojindo). Briefly, $10 \mu \mathrm{l} \mathrm{CCK-8} \mathrm{reagents} \mathrm{were} \mathrm{incubated} \mathrm{with} \mathrm{cells} \mathrm{for} \mathrm{one} \mathrm{hour,} \mathrm{and} \mathrm{then,} \mathrm{the}$ absorbance at $450 \mathrm{~nm}$ was measured with a microplate reader. For plate colony formation assay, 500 cells/well were cultured in 6-well plates for 1 week. The colony were counted after fixation with $4 \%$ formaldehyde for $5 \mathrm{~min}$ and staining with $0.1 \%$ crystal violet for $10 \mathrm{~min}$ at room temperature.

\section{Cell migration and invasion assays}

Cells $\left(1 \times 10^{4}\right)$ pretreated with $10 \mu \mathrm{g} / \mathrm{ml}$ mitomycin-C (Sigma) for $1 \mathrm{~h}$ at $37^{\circ} \mathrm{C}$ were added into the upper chamber of a Transwell with $8.0 \mu \mathrm{m}$ pore polycarbonate membrane insert in $100 \mu \mathrm{L}$ of RPMI 1640 medium containing $1 \%$ FBS. Five hundred microliters of RPMI 1640 with $10 \%$ FBS was added into the lower chamber as a chemoattractant. Twenty-four hours later, the cells were fixed for 5 min with $4 \%$ formaldehyde and stained with $1 \%$ crystal violet for $1 \mathrm{~min}$ at room temperature. After removing the cells inside of membrane, the number of migrated and invasive cells were photographed in four randomly selected microscopic fields.

\section{In vivo tumor growth and metastasis}

A modified chick embryo chorioallantoic membrane (CAM) assay was used to access tumor growth and metastatic characteristics. Briefly, (10-day-old SPF white leghorn chicken embryos eggs (Beijing Merial 
Vital Laboratory Animal Technology Co., Ltd) were randomized into groups ( $n=5)$. A square window was opened in the shell under aseptic conditions after sterilization with $75 \%$ ethanol. $5 \times 10^{6}$ cells in $50 \mu \mathrm{l}$ PBS were labeled with CM-Dil (red fluorescent dye) in $5 \%$ glucose for $15 \mathrm{~min}$ at $37^{\circ} \mathrm{C}$, and inoculated onto the each CAM. Eggs were resealed with sterilized tape and returned to a humidified $37^{\circ} \mathrm{C}$ incubator for additional 7 days. Animals were executed after the experiment and the tumors grew on the each CAM were dissected and weighed. To track the distant metastatic tumor cells, the lungs were isolated, flattened by two slides and evaluated under a fluorescence microscope (Leica).

\section{Immunoblotting}

Cells or tumor tissues were lysed with radio immunoprecipitation assay (RIPA) buffer containing a protease inhibitor cocktail (Roche). Protein concentration was assessed with a BCA protein assay kit (BioRad Laboratories). Equal amounts of protein for each sample $(30 \mu \mathrm{g})$ were separated on 10\% SDS-PAGE gels, and subsequently transferred to PVDF membranes (Millipore). The membranes were blocked for $1 \mathrm{~h}$ in PBS containing 5\% nonfat milk and then incubated overnight with the SFRP2 and DKK1 antibody diluted to $1: 5000$ at $4^{\circ} \mathrm{C}$. The membranes were then incubated with HRP-conjugated secondary antibodies and visualized with ECL detection reagents (Millipore). Images were captured by Al600 version 1.2.0 on an Amersham Imager 600 (GE Healthcare).

\section{RNA pull-down}

For the in vivo pull-down assay, LINC00238-6×MS2bs plasmids containing 6 repeat MS2-binding site RNA sequences and MS2 expression plasmids with Flag tags were co-transfected into cells, and then, isolated using anti-Flag-conjugated magnetic beads (Sigma). Biotin based pull-down assays were carried out according to the manufacturer's protocol. Briefly, RNAs were incubated with biotinylated probes for 30 min at room temperature, and isolated using streptavidin-conjugated Dynabeads (Dynal). The pull-down RNAs were isolated, purified, synthesized cDNA, and qualified the gene expression by q-PCR.

\section{Reporter gene assay}

To determine the relative luciferase activity, cells were seeded into 24-well plates, and co-transfected with $500 \mathrm{ng}$ of pGL3-control containing LINC00238, $26 \mathrm{ng}$ of pRL-TK plasmid expressing Renilla luciferase, and 20 pmol of miR-522 mimics or NC using Lipofectamine $2000(n=4)$. Firefly and Renilla luciferase activity in the cell lysates were measured $24 \mathrm{~h}$ after transfection using a dual-luciferase reporter assay kit (Promega). Firefly luciferase activity was normalized to that of Renilla luciferase for each sample.

\section{Statistical analysis}

Data were analyzed with SPSS 26 and GraphPad Prism 8. Nonparametric testing was used to compare the LINC00238 expression in the GC and normal tissues. Chi-Square test was used to analyze the LINC00238 expression and the clinical pathological characteristics. Kaplan-Meier method was used to analyze the survival. The continuous variables with normal distribution and equal variance (F-test) 
between/within the groups are expressed as the Mean \pm S.D., and the statistical significance was determined using a two-tailed Student's t-test between two groups, using one-way ANOVAs with Bonferroni post hoc tests for multiple comparisons, and using Two-way ANOVA for cell viability analysis. Two tailed test with $P<0.05$ was considered a statistically significant difference.

\section{Results}

\section{Identification of the down-regulated IncRNAs in HCC tissues}

A total of 15 down-regulated IncRNAs were screened out in Hepatocellular Carcinoma tissues by GEPIA (http://gepia.cancer-pku.cn, FC>2, $P_{a d}<0.01$, supplementary Table 1). Next, K-M survival analysis suggested that five lincRNAs (LINC01554, LINC01093, LINC01018, LINC01370, LINC00238) were associated with overall survival of patients after surgery by Median expression level of each lincRNA (supplementary Table 1 and supplementary Fig.1, $P<0.1$ ). LINC01554 [7, 8], LINC01093 [9, 10], LINC01018 [11, 12] had been reported in Hepatocellular Carcinoma, whereas LINC01370 and LINC00238 had not. As shown in the Fig 1A\&B, the expression of LINC00238 was significantly decreased in the HCC tissues compared with normal tissues from the analysis by GEPIA website. In addition, as indicated in the Fig 1C, LINC00238 was also down-regulated in 91.8\% (45/49, $P<0.0001)$ HCC tissues by paired student's t-test analysis of matched and normal tissues from TCGA dataset. Kaplan-Meier (K-M) survival curves indicated that patients with high LINC00238 expression showed longer overall survival time (Figure 1D, median survival 80 months versus 50 months, hazard ratio for death $=0.74, P=0.099$ ).

\section{Low levels of LINC00238 expression in HCC tissues correlated with bigger tumor size, early recurrence and poor survival of patients after surgery}

To validate these results from TCGA, we qualified LINC00238 expression in our own 90 cases of HCC cohort. Consistently, LINC00238 expression was decreased in 83.33\% (75/90) HCC tissues compared with adjacent tissues (Figure 1E\&F, $P<0.001$ ). To facilitate analysis, we divide patients into low and high LINC00238 group according to its median expression level in HCC tissues. As shown in Table I, low expression of LINC00238 was associated with bigger tumor size, early recurrence and shorter survival time. The proportion of low LINC00238 expression was higher in the tumor tissues of patients with bigger tumor size (56.92\% vs $43.08 \%, c^{2}$ test, $\left.P=0.034\right)$, higher ratio of early recurrence within 2 years after surgery $\left(66.67 \%\right.$ versus $33.33 \%, c^{2}$ test, $\left.P=0.003\right)$, higher $\mathrm{N}$ stage ( $\mathrm{c}^{2}$ test, $P=0.011$ ) and less overall survival time of 4 years ( $c^{2}$ test, $P=0.030$ ), indicating that low LINC00238 expression may be associated with tumor progression. However, there was no association between LINC00238 expression and other clinicopathological features, including sex, age, hepatic cirrhosis and venous invasion $\left(c^{2}\right.$ test, $P>0.05$, Table I). We then assessed the association between LINC00238 expression and OS of patients with HCC. Consistent with the above results from GEPIA website, Kaplan-Meier survival analysis revealed that patients with low LINC00238 expression exhibited a significantly shorter OS खMedian 47.4 vs 62.4 months, $P=0.050$ \and DFS (Median 12.7 vs 60.0 months, $P=0.026$ ) compared with those with high expression (Fig. 1G\&H). 


\section{LINC00238 overexpression impairs HCC malignant phenotype in vitro}

We then quantified LINC00238 expression in on human normal hepatic L02 cells and HCC cells, including HepG2, SMMC-7721, PLC/PRF/5, BEL-7402 and Huh7. The LINC00238 was significantly down-expressed in all HCC cells compared to L02 cells (Fig. 2A). We chose Huh7 cells (relatively low LINC00238 expression) for the overexpression experiments and HepG2 cells (relatively high LINC00238 expression) for the knockdown experiments. Compared to control cells, LINC00238 expression was increased by 24 fold times after overexpression as detected qPCR (Fig. 2B). Forced expression of LINC00238 suppressed Huh7 cell viability (Fig. 2C) and colony formation (Fig. 2D, about $47.9 \%$ inhibition). In addition, forced expression of LINC00238 significantly decreased the migratory and invasive ability of the Huh7 cells, as determined by Transwell assay (Fig. 2E, about $40.0 \%$ inhibition for cell migration and $36.9 \%$ inhibition for cell invasion). These in vitro findings suggested that LINC00238 might act as tumor suppressor in HCC.

\section{Knockdown of LINC00238 promotes HCC malignant phenotype in vitro}

We knocked down the expression of LINC00238 in HepG2 cells using three shRNAs targeting different sites. Three shRNAs had $82 \%, 88 \%$ and $72 \%$ knockdown efficiency respectively (Fig. 3A), and two silencers, shRNA1 and shRNA2, were choose in subsequent experiments. The CCK-8 assay and plate colony formation assay results demonstrated that LINC00238 depletion promoted cell viability (Fig. 3B) and colony formation ability of HepG2 (Fig. 3C). Furthermore, Transwell assay results showed that inhibition of LINC00238 significantly enhanced the migration and invasive ability of Hep2 cells with the two shRNAs (Fig. 3D).

\section{LINC00238 functioned as tumor suppressor in vivo}

To further confirm the suppression effect in HCC by LINC00238 in vivo, we performed a modified chick embryo chorioallantoic membrane (CAM) assay to assess the tumor growth and metastasis. Cells labeled with red fluorescence were inoculated onto CAM to monitor tumor growth and distance metastasis to lung tissues of chick embryo. Compared to the control cells, overexpression of LINC00238 resulted in a decrease of tumor weight by $64.8 \%$ (Fig. 4A). Moreover, the number of metastatic tumor colonies, which represented metastasis ability to lung tissues, were decreased by $80.9 \%$ in cells after LINC00238 over-expression (Fig. 2B). Consistently, knocking down of LINC00238 expression resulted in a significant increase in not only the tumor weight but also the extent of metastasis to the lungs (Fig. $3 \mathrm{C}$ and 3D) by CAM assay. Notably, metastatic nodules in lung tissues of the LINC00238 shRNA groups were significantly more than those of the scramble group (Fig. 3D). Hence, the reciprocal effects of LINC00238 overexpression and knockdown both in vitro and in vivo supported that LINC00238 played a tumor suppressor in HCC.

\section{LINC00238 sponges miR-522 to regulate malignant phenotype in HCC}

Cytoplasm IncRNAs can regulate cell phenotype by sponging miRNAs. The prediction by IncLocator (http://www.csbio.sjtu.edu.cn/cgi-bin/IncLocator.py) suggested that LINC00238 is predominantly located 
in the cytoplasm. Consistently, the nucleus cytoplasm separation experiments confirmed that LINC00238 distributed mainly in the cytoplasm (Figure 5A), which suggested that LINC00238 might sponge miRNAs. Bioinformatics software predicted that the seed regions of miR-522 was complementary with three isotypes of LINC00238 (Figure 5B). Furthermore, the expression of miR-522 showed decreased in LINC00238 over-expression Huh7 cells, but increased in the LINC00238 knock-down HepG2 cells (Figure 5C). Then, RNA pull-down experiments suggested that expression of miR-522 was enriched about 8.3 times by LINC00238 compared with control group (Figure 5D). In addition, the expression of LINC00238 in the biotin-miR-522 group was about 5.8 times that of the negative control group (Figure 5E). We constructed wild-type and mutant versions of LINC00238 downstream of the luciferase gene using PGL3control vector (Figure 5G). By a dual-luciferase report assay, overexpression of miR-522 was associated with a decrease of luciferase activity of LINC00238 wild type of vector, but had no effect on the mutant type of vector (Figure $5 \mathrm{H}$ ). Previously, it had reported that miR-522 contributes to cell proliferation of hepatocellular carcinoma by targeting two Wnt signaling inhibitors, DKK1 and SFRP2 [13]. We therefore confirmed that whether LINC00238 release the inhibition effect on these target genes of miR-522. Consistent with the hypothesis, SFRP2 and DKK1 were increased in both Huh7 cells and tumors after over-expression of LINC00238, but decreased in HepG2 cells and tumors after interference expression of LINC00238. Taken together, LINC00238 might regulate malignant phenotype in HCC by sponging miR522 followed by release the inhibition of down-stream targets of miR-522.

\section{Rescue expression miR-522 reverse suppression effects of LINC00238 partially}

To corroborate the key role of miR-522, we performed a gain-of-function experiment in Huh7-LINC00238 cells by using miR-522 mimics (Fig. 6A). The expression of miR-522 was enhanced by 186 times after transfection with mimics. Consistent with our prediction and previous report [13], rescue of miR-522 partially reversed the inhibitory effects of LINC00238 on Huh7 cell viability (Fig. 6B), plate colony formation ability (Fig. 6C), migration and invasion ability (Fig. 6D), tumor growth (Fig. 6E) and metastasis to the lungs (Fig. 6F) in the CAM assay. Two known downstream targets of miR-522囚SFRP2 and DKK1, was inhibited in both Huh7-LINC00238 cells and tumors after transfection with mimics. These results consolidated that LINC00238 functioned as tumor suppressor through sequestering miR-522, thereby relieving the inhibition of SFRP2 and DKK1at least partially.

\section{Discussion}

In this study, we propose a novel function for LINC00238 in malignant phenotype regulation of HCC. Our results suggest that LINC00238 expression decreases in HCC tissues and serves as a competing endogenous RNAs (ceRNA), inhibits tumor cell growth and migration by sponging oncomiR-522 via relieving the inhibition of targeting two tumor suppressors SFRP2 and DKK1 (Fig. 7).

We assessed differential expression genes (DEGs) in HCC and normal tissues by using a web server for cancer and normal gene expression profiling and interactive analyses, GEPIA [14]. Among these DEGs, 15 down-regulated known IncRNAs were screened out and LINC00238 was selected for further study. 
LINC00238 has been reported to be significantly down-regulated in after in liver tissues and liver cells after HBV infection [6]. It is noteworthy that Chronic HBV infection accounts for about $50 \%$ cases of HCC worldwide [15], but LINC00238 has not been studied in HCC before. A considerable number of studies have examined that IncRNAs, either as oncogene or suppressor gene, function as ceRNAs in HCC. For example, HOXD-AS1 as an oncogene sponges regulatory miR-130a-3p to enhance the expression of the transcription factors SOX4, resulting in a promotion of HCC metastasis [16]. LincRNA CASC2, a novel tumor suppressor, exerted anti-metastatic effects through miR-367/FBXW7 axis in HCC cells [17]. Previous work suggests that IncRNAs in cytoplasm function as molecular sponges or modulate mRNA stability [18]. Here, LINC00238 was identified as be located in the cytoplasm and considered as a ceRNA to regulate HCC progression. Our RNA binding immunoprecipitation assay suggested that LINC00238 had the potential to interact with miR-522. Dual luciferase report and biotin-miR-522 pull-down assay also revealed that LINC00238 is a target of miR-522. It is well known that miR-522 is an oncogene in many cancers including HCC [19], lung cancer [20] et.al. SFRP2 and DKK1, two known Wnt signaling inhibitors involved in hepatitis $C$ virus-induced multistep hepatocarcinogenesis [21], were already identified as two direct targets of miR-522 in HCC cells [13].

\section{Conclusions}

We speculated that the suppression effects of LINC00238 on HCC malignant phenotype might be due to miR-522-mediated regulation of SFRP2 and DKK1. The ceRNA regulatory network (LINC00238/miR-522/ SFRP2 and DKK1) sheds light on the mechanisms of lincRNA regulation of HCC development. It is worth pointing out that LINC00238 might regulate HCC progression through other mechanisms as well, such as regulation of mRNA stability.

\section{Abbreviations}

$\mathrm{HCC}$

Hepatocellular Carcinoma; IncRNA:Long noncoding RNA; TCGA:The Cancer Genome Atlas; LIHC:Liver hepatocellular carcinoma; GEPIA:Gene Expression Profiling Interactive Analysis; qRT-PCR:Real-Time Quantitative Reverse Transcription PCR; CCK-8:Cell Counting Kit-8; SFRP2:Secreted Frizzled Related Protein 2; DKK1:Dickkopf1.

\section{Declarations}

\section{Ethics approval and consent to participate}

This study was approved by the Ethics Committee of Peking University Cancer Hospital \& Institute.

\section{Consent to publish}

Not applicable. 
Availability of data and materials

All relevant materials and data are available for non-commercial purposes.

\section{Competing interests}

All authors declare no competing interest.

\section{Funding}

Not applicable.

\section{Authors' Contributions}

$\mathrm{HQ}$ and $\mathrm{CH}$ designed the research, performed and wrote the manuscript. QW analyzed the data. JW, XT and WX helped the collection and analysis of the clinical data. All authors approved the final manuscript.

\section{Acknowledgements}

Not applicable.

\section{References}

1. Siegel RL, Miller KD, Jemal A. Cancer statistics, 2019. CA Cancer J Clin. 2019;69(1):7-34.

2. Chen W, Zheng R, Baade PD, Zhang S, Zeng H, Bray F, Jemal A, Yu XQ, He J. Cancer statistics in China, 2015. CA Cancer J Clin. 2016;66(2):115-32.

3. Anwanwan D, Singh SK, Singh S, Saikam V, Singh R. Challenges in liver cancer and possible treatment approaches. Biochim Biophys Acta Rev Cancer. 2020;1873(1):188314.

4. Mikhail S, Cosgrove D, Zeidan A. Hepatocellular carcinoma: systemic therapies and future perspectives. Expert Rev Anticancer Ther. 2014;14(10):1205-18.

5. Lim LJ, Wong SYS, Huang F, Lim S, Chong SS, Ooi LL, Kon OL, Lee CG. Roles and Regulation of Long Noncoding RNAs in Hepatocellular Carcinoma. Cancer Res. 2019;79(20):5131-9.

6. Qin HUANGZZ, Quanbo LIU. Effect of long intergenic non-coding RNA 238 on HBV replication and expression in vitro. Journal of Third Military Medical University. 2018;40(21):1942-7.

7. Zheng YL, Li L, Jia YX, Zhang BZ, Li JC, Zhu YH, Li MQ, He JZ, Zeng TT, Ban XJ, et al. LINC01554Mediated Glucose Metabolism Reprogramming Suppresses Tumorigenicity in Hepatocellular Carcinoma via Downregulating PKM2 Expression and Inhibiting Akt/mTOR Signaling Pathway. Theranostics. 2019;9(3):796-810.

8. Ding Y, Sun Z, Zhang S, Chen Y, Zhou B, Li G, Sun Q, Zhou D, Ge Y, Yan S, et al. Down-regulation of Long Non-coding RNA LINC01554 in Hepatocellular Cancer and its Clinical Significance. J Cancer. 
2020;11(11):3369-74.

9. He J, Zuo Q, Hu B, Jin H, Wang C, Cheng Z, Deng X, Yang C, Ruan H, Yu C, et al. A novel, liver-specific long noncoding RNA LINC01093 suppresses HCC progression by interaction with IGF2BP1 to facilitate decay of GLI1 mRNA. Cancer Lett. 2019;450:98-109.

10. Zheng Y, Yu K, Huang C, Liu L, Zhao H, Huo M, Zhang J. Integrated bioinformatics analysis reveals role of the LINC01093/miR-96-5p/ZFAND5/NF-kappaB signaling axis in hepatocellular carcinoma. Exp Ther Med. 2019;18(5):3853-60.

11. Wang S, Xu M, Sun Z, Yu X, Deng Y, Chang H. LINC01018 confers a novel tumor suppressor role in hepatocellular carcinoma through sponging microRNA-182-5p. Am J Physiol Gastrointest Liver Physiol. 2019;317(2):G116-26.

12. Wen Q, Wang D, Yang Y, Chen X, Pan X, Han Q, Deng Y, Li X, Chen X, Yan J, et al. Competing endogenous RNA screening based on long noncoding RNA-messenger RNA co-expression profile in Hepatitis B virus-associated hepatocarcinogenesis. J Tradit Chin Med. 2017;37(4):510-21.

13. Zhang H, Yu C, Chen M, Li Z, Tian S, Jiang J, Sun C. miR-522 contributes to cell proliferation of hepatocellular carcinoma by targeting DKK1 and SFRP2. Tumour Biol. 2016;37(8):11321-9.

14. Tang Z, Li C, Kang B, Gao G, Li C, Zhang Z. GEPIA: a web server for cancer and normal gene expression profiling and interactive analyses. Nucleic Acids Res. 2017;45(W1):W98-102.

15. Xie Y. Hepatitis B Virus-Associated Hepatocellular Carcinoma. Adv Exp Med Biol. 2017;1018:11-21.

16. Wang H, Huo X, Yang XR, He J, Cheng L, Wang N, Deng X, Jin H, Wang N, Wang C, et al. STAT3mediated upregulation of IncRNA HOXD-AS1 as a ceRNA facilitates liver cancer metastasis by regulating SOX4. Mol Cancer. 2017;16(1):136.

17. Wang Y, Liu Z, Yao B, Li Q, Wang L, Wang C, Dou C, Xu M, Liu Q, Tu K. Long non-coding RNA CASC2 suppresses epithelial-mesenchymal transition of hepatocellular carcinoma cells through CASC2/miR-367/FBXW7 axis. Mol Cancer. 2017;16(1):123.

18. Fatica A, Bozzoni I. Long non-coding RNAs: new players in cell differentiation and development. Nat Rev Genet. 2014;15(1):7-21.

19. Shi YH, Qi BB, Liu XB, Ding HM. Upregulation of miR-522 is associated with poor outcome of hepatocellular carcinoma. Eur Rev Med Pharmacol Sci. 2016;20(15):3194-8.

20. Zhang T, Hu Y, Ju J, Hou L, Li Z, Xiao D, Li Y, Yao J, Wang C, Zhang Y, et al: Downregulation of miR522 suppresses proliferation and metastasis of non-small cell lung cancer cells by directly targeting DENN/MADD domain containing 2D. Sci Rep 2016, 6:19346.

21. Umer M, Qureshi SA, Hashmi ZY, Raza A, Ahmad J, Rahman M, Iqbal M. Promoter hypermethylation of Wnt pathway inhibitors in hepatitis $C$ virus - induced multistep hepatocarcinogenesis. Virol $\mathrm{J}$. 2014;11:117.

\section{Tables}


Table 1

Correlation between LINC00238 expression and the clinicopathologic features in 90 HCC patients

\begin{tabular}{|llll|}
\hline \multirow{2}{*}{ Variable } & \multicolumn{2}{l}{ LINC00238 expression } & \multirow{2}{*}{ P value $^{\text {a }}$} \\
\cline { 2 - 3 } & Low (\%) & High (\%) & \\
\hline Sex & & & \\
\hline Male & $40(50.63 \%)$ & $39(49.37 \%)$ & 0.748 \\
\hline Female & $5(45.45 \%)$ & $6(54.55 \%)$ & \\
\hline Age & & & \\
\hline$\leq 60$ & $34(53.13 \%)$ & $30(46.88 \%)$ & 0.352 \\
\hline$>60$ & $11(42.31 \%)$ & $15(57.69 \%)$ & \\
\hline Hepatic cirrhosis & & & \\
\hline Absent & $14(46.67 \%)$ & $16(53.33 \%)$ & 0.655 \\
\hline Present & $31(51.67 \%)$ & $29(48.33 \%)$ & \\
\hline Size & & & \\
\hline$\leq 3$ cm & $8(32.00 \%)$ & $17(68.00 \%)$ & $0.034 *$ \\
\hline$>3$ & $37(56.92 \%)$ & $28(43.08 \%)$ & \\
\hline Venous invasion & & & \\
\hline Absent & & & \\
\hline Present & $32(47.06 \%)$ & $36(52.94 \%)$ & 0.327 \\
\hline Recurrence & $13(59.09 \%)$ & $9(40.91 \%)$ & \\
\hline Early(within 2 years) & $28(66.67 \%)$ & $14(33.33 \%)$ & $0.003 *$ \\
\hline Late (4 years after surgery) ${ }^{c}$ & $17(35.42 \%)$ & $31(64.58 \%)$ & \\
\hline Survival time & & & \\
\hline Less than 4 years & & & \\
\hline More than 4 years & & & \\
\hline Note: a, Chi-Square test. & & & \\
\hline
\end{tabular}


A

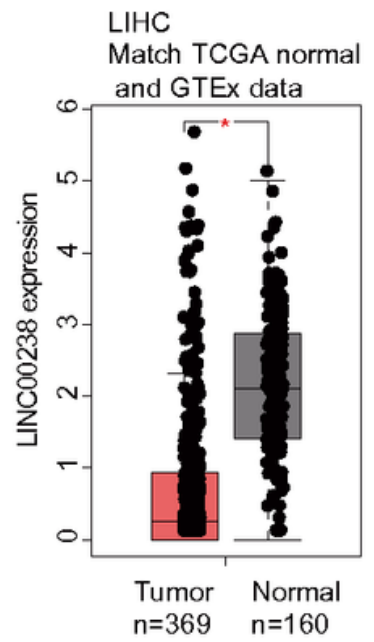

D

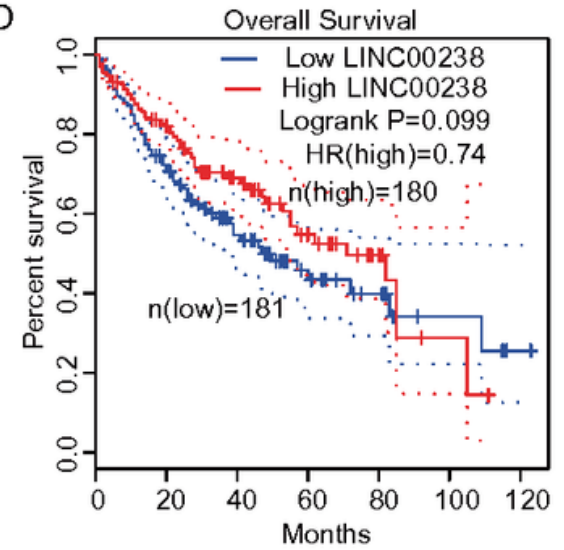

G

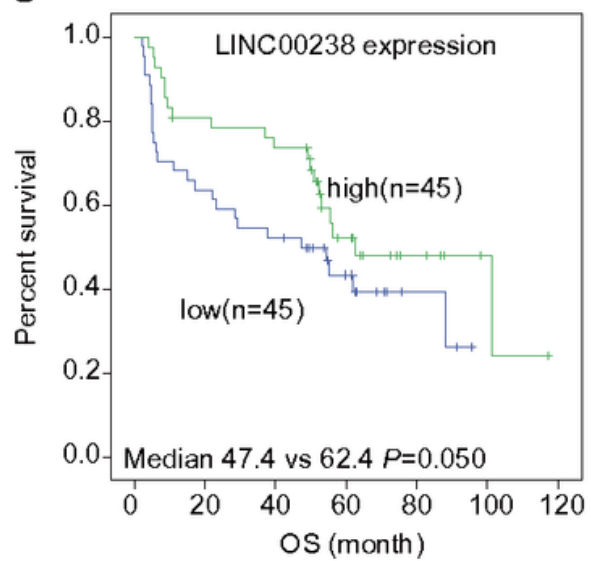

B

LIHC

Match TCGA normal data

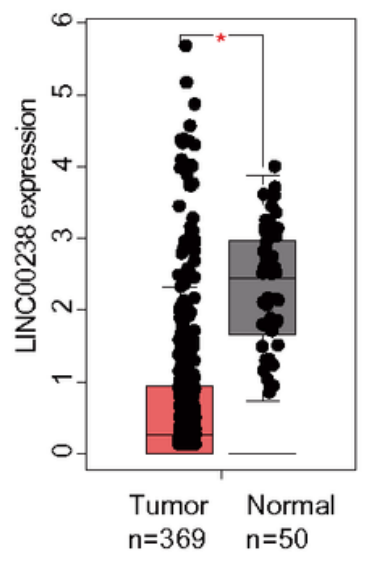

E

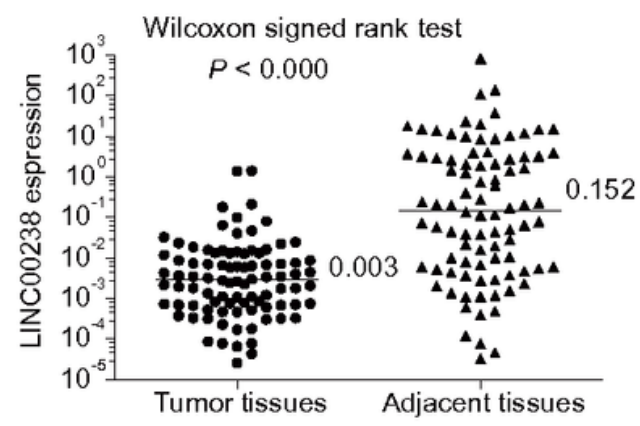

$\mathrm{H}$

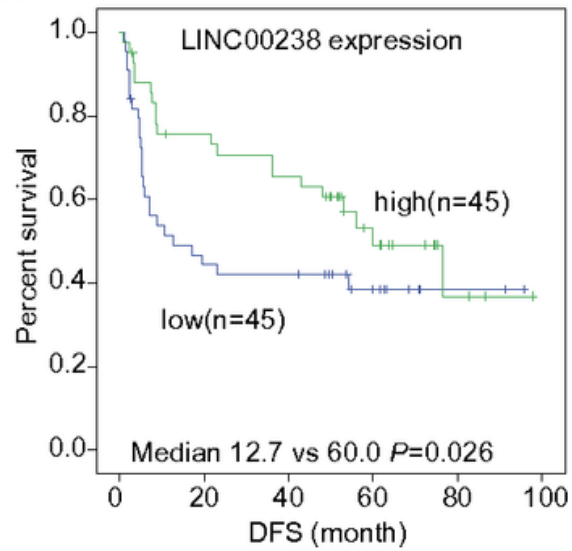

F

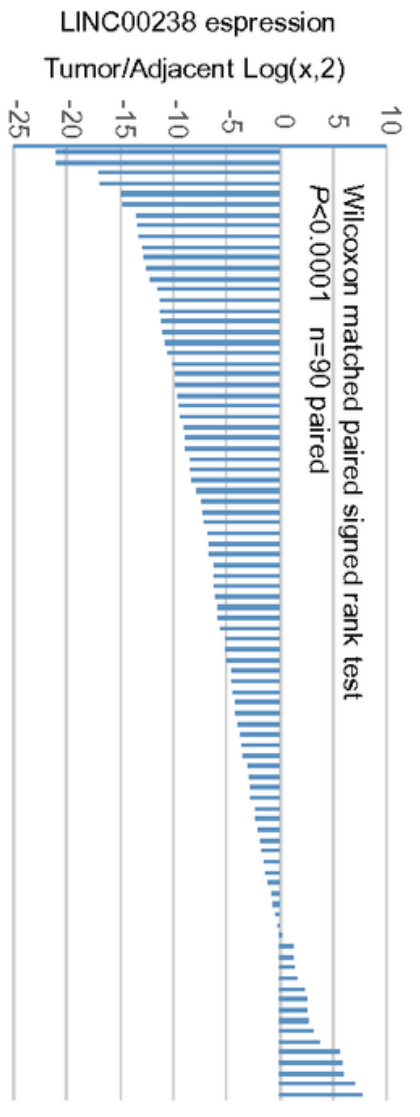

Figure 1

Low levels of LINC00238 expression correlate with poor prognosis of patients with HCC. A,B. Analysis the LINC00238 in HCC and normal tissues from the TCGA and GEO database by GEPIA website. C. The expression analyses of LINC00238 in 49 pairs of HCC and matched normal tissues from TCGA database. D. Kaplan-Meier analysis of overall survival from TCGA database revealed that patients with lower expression of LINC00238 in tumor tissues had predictable poor prognosis. E, F. The expression level of LINC00238 in 90 cases of primary HCC tumor and adjacent tissues from our cohort, as determined by q- 
PCR by population or paired analysis. The lines in E indicate the median of each group. G,H. KaplanMeier analysis of overall (OS) and disease-free survival (DFS) revealed that patients with lower LINC00238 expression in tumor tissues had predictable poor prognosis.

A

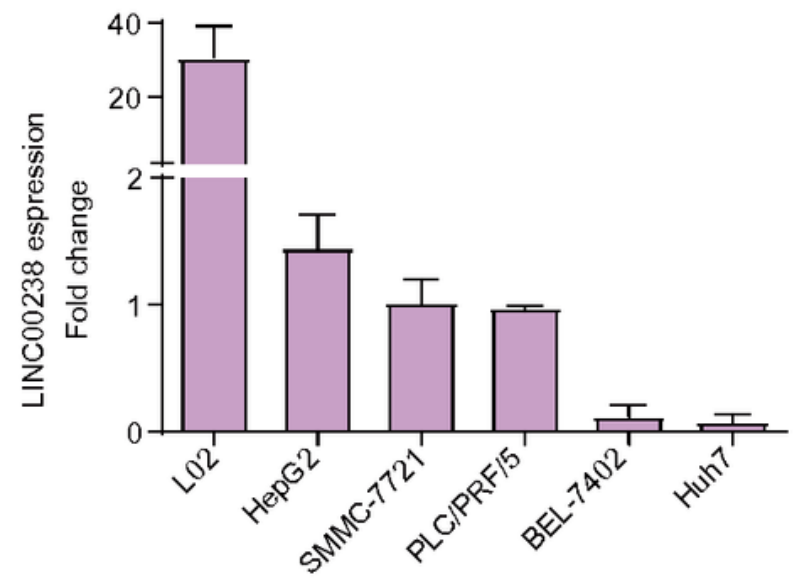

B

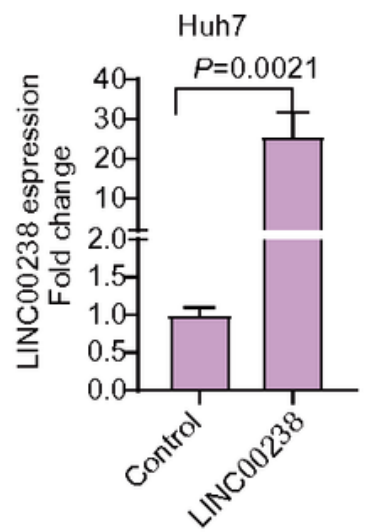

C

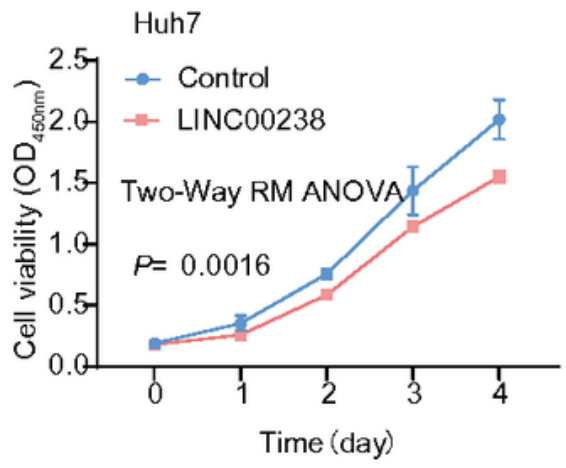

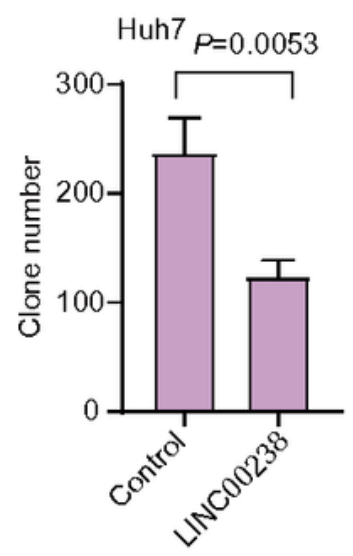

$\mathrm{E}$

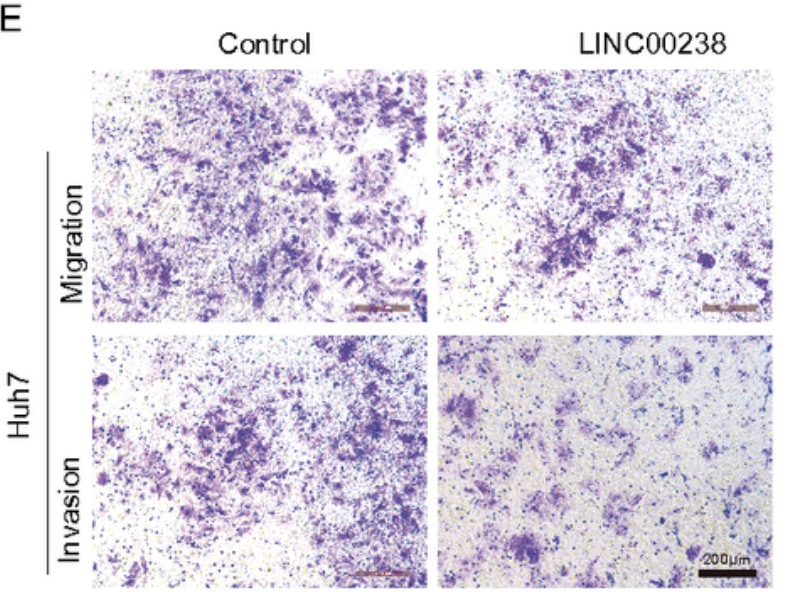

Huh7

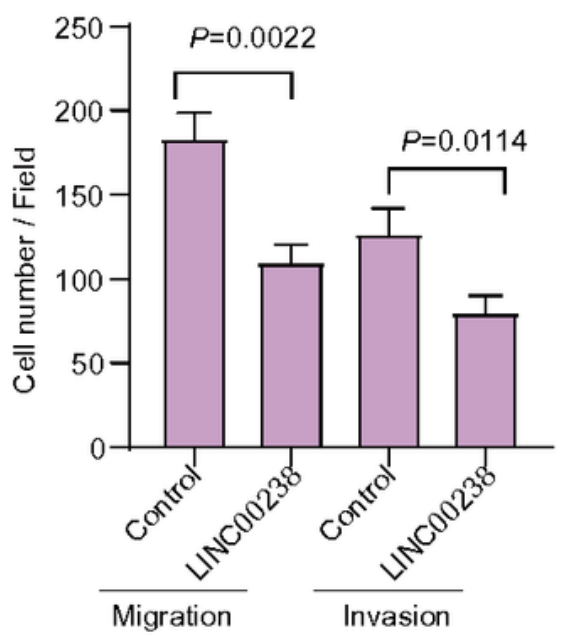

Figure 2

Forced LINC00238 expression inhibits GC cell viability, invasion and migration in vitro. A, B. Expression levels of LINC00238 in cells were determined by q-PCR. C. CCK-8 assays were performed to access cell 
viability. D. Plate colony formation assays were performed to monitor cell growth. E. Transwell assays were performed to investigate cell migration and invasion. The number of cells was counted in four different fields. Scale bars, $200 \mu \mathrm{m}$.

A

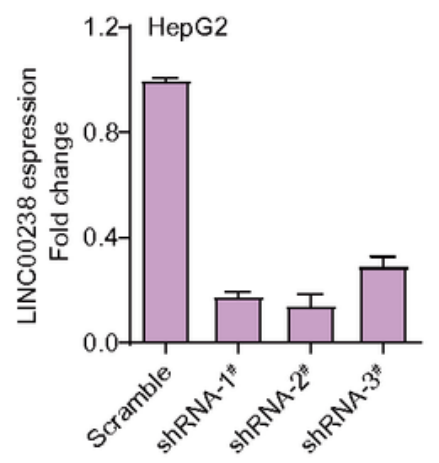

B

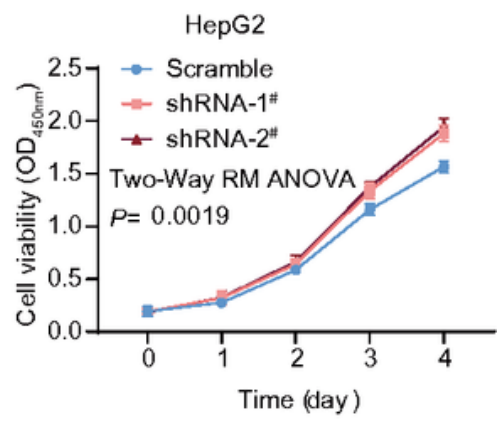

C

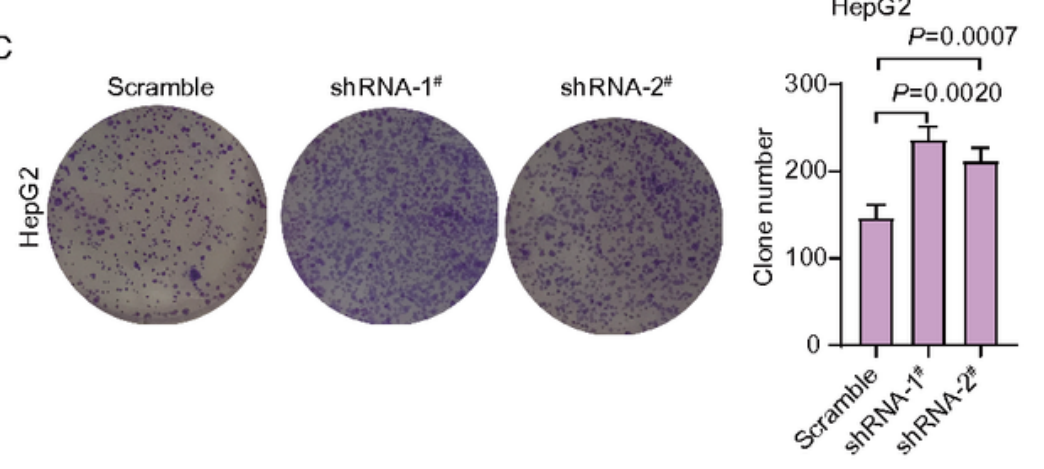

D
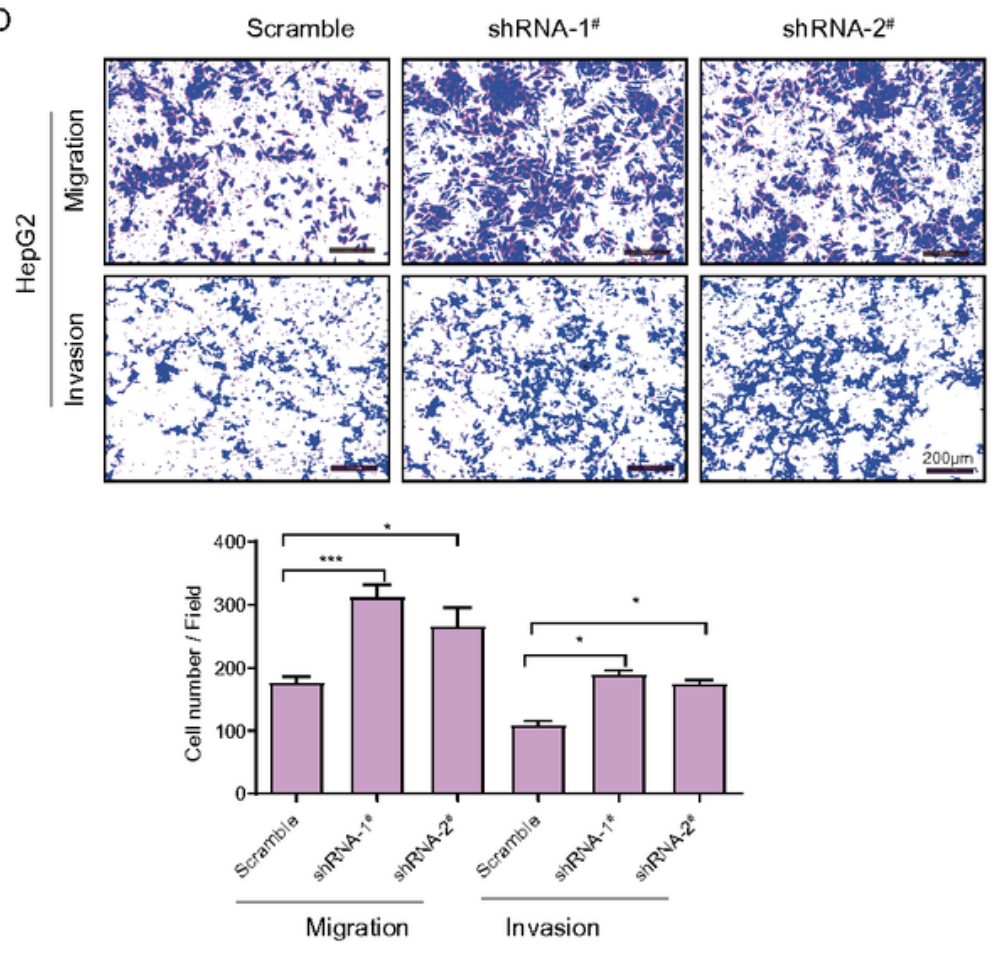

Figure 3

Knockdown of LINC00238 promotes GC cell viability, invasion and migration in vitro. HepG2 cells were infected with Lv-shRNA to establish three cell lines with stably depletion LINC00238 expression. A. 
Expression of LINC00238 in the HepG2 cells after shRNA-mediated knockdown of LINC00238 was detected by qPCR. B. CCK-8 assays were performed to monitor cell viability. C. Plate colony formation assays were performed to detect cell growth. D. Transwell assays were performed to determine cell migration and invasion. The number of cells was counted in four different fields. Scale bars, $200 \mu \mathrm{m}$.
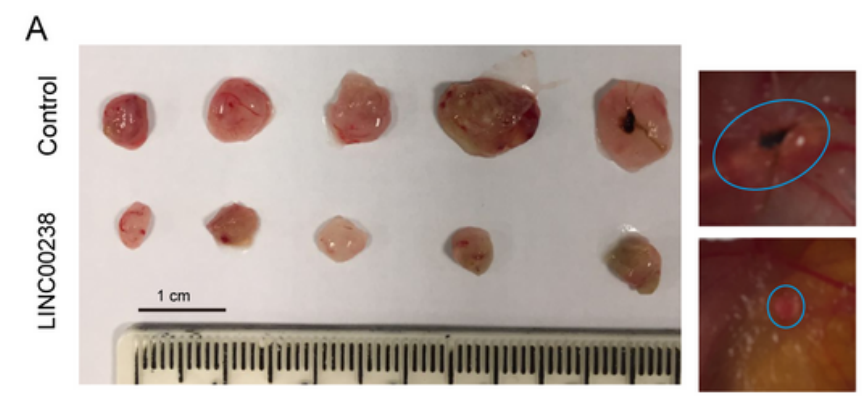

C
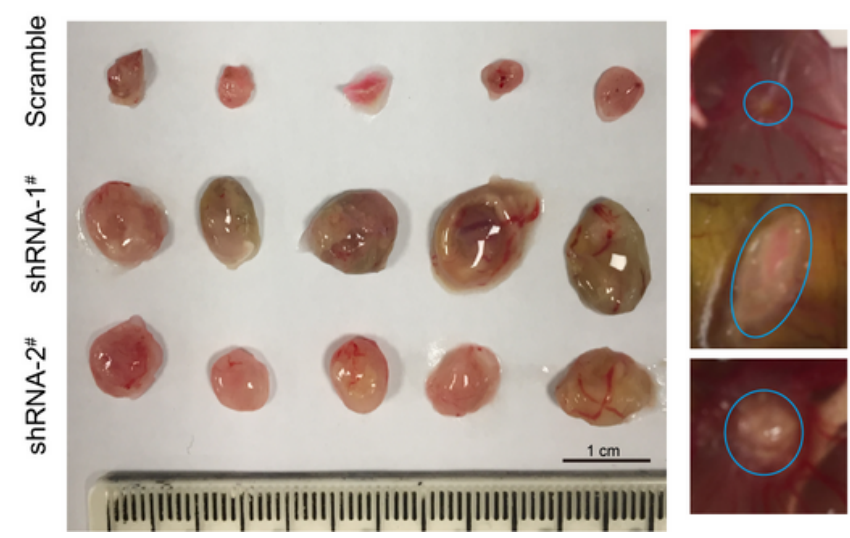

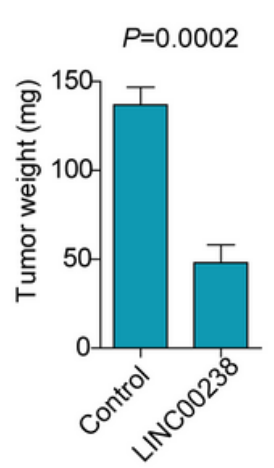

B
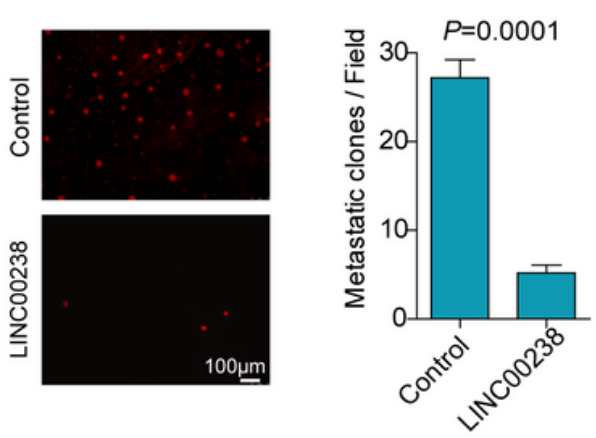

D

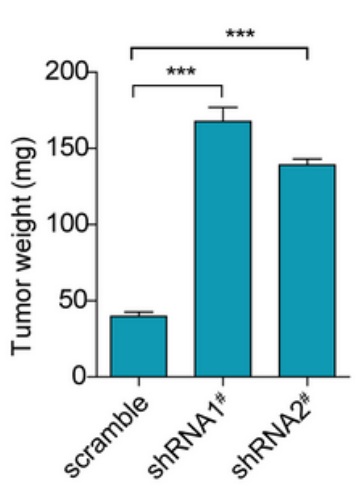

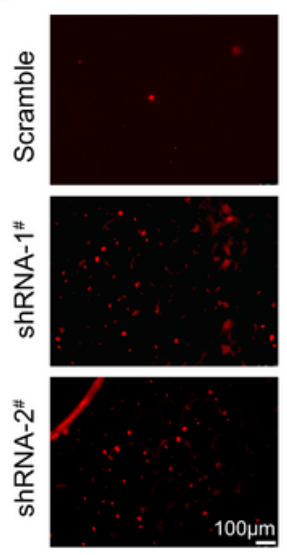

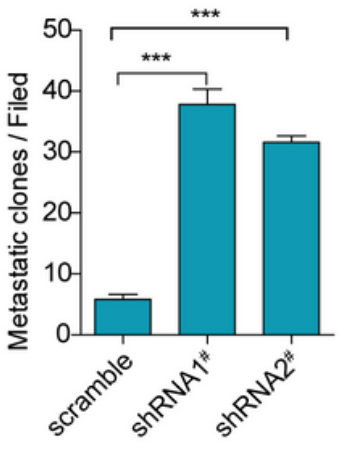

\section{Figure 4}

LINC00238 promotes tumor growth and progression in vivo A, C. Huh7 control cells or cells with stable LINC00238 over-expression were inoculated onto the CAM. The effect of LINC00238 on HCC tumor growth was evaluated based on the tumor weight of each group. B, D. Representative pictures of lung metastasis lesion by a laser scanning confocal microscope. The effect of LINC00238 on lung metastasis was evaluated by the number of metastatic lesion (tumor cells labeled with red fluorescent dye CM-Dil). The data in the bar graphs were calculated as the mean \pm S.D. for each group; $* \star \star P<0.001$. 

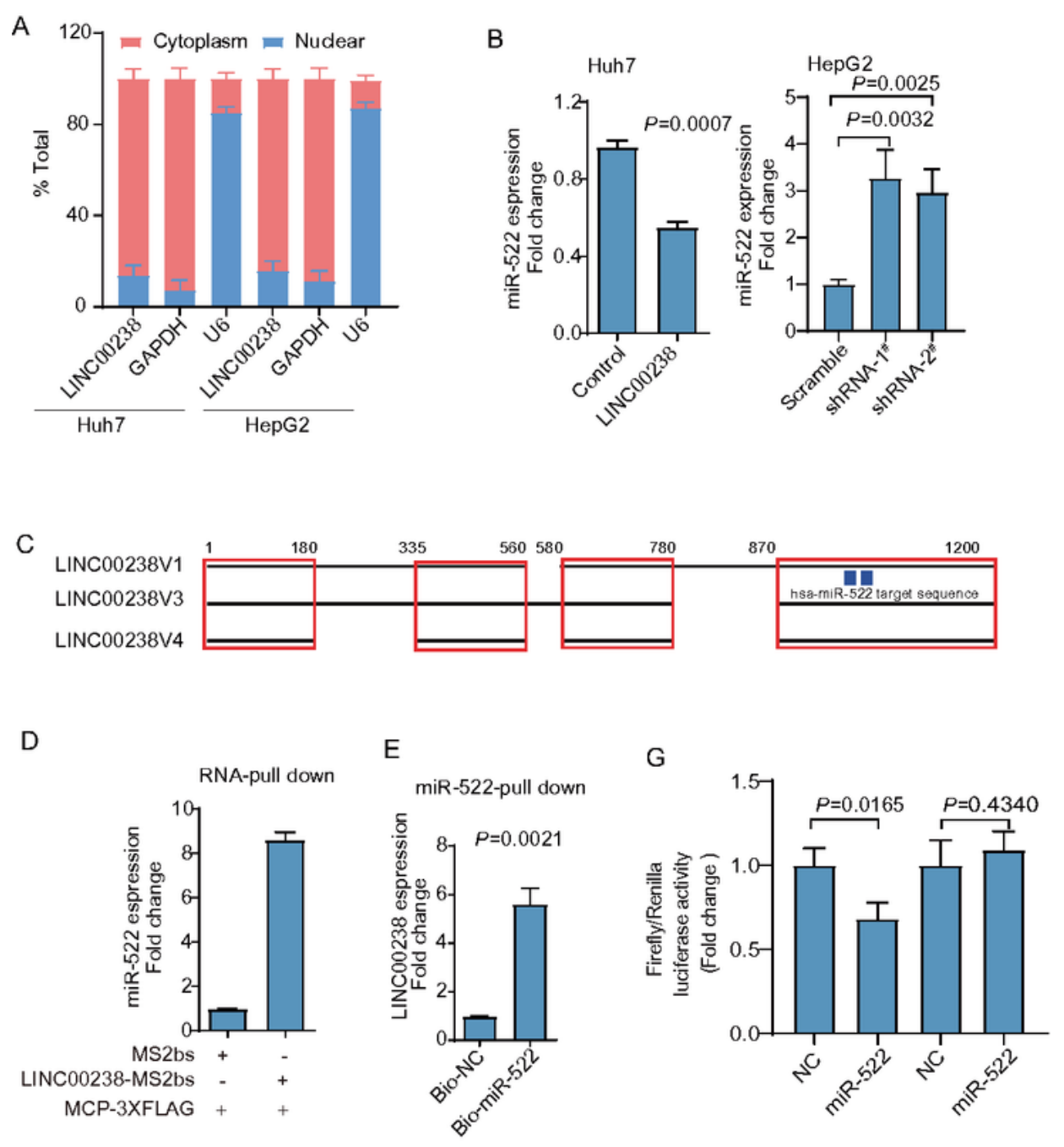

$\mathrm{F}$
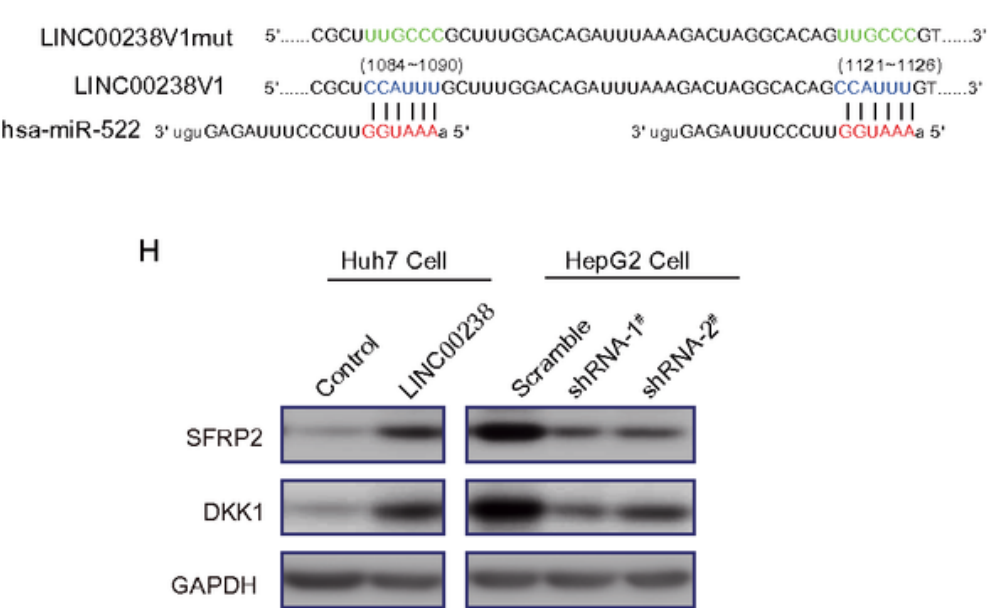

Figure 5

Cytoplasmic LINC00238 sponges miR-522. A. The bar graphs showed subcellular distribution of LINC00238 calculated by real time qPCR assay in Huh7 and HepG2 cells. Cytoplasmic control (GAPDH) and nuclear control (U6) were determined in their expected localization. B. The expression of miR-522 was detected by q-PCR in over-expression and depletion LINC00238 cells. C, D. In vivo and in vitro RNA pull-down assays were performed. The pull-down RNA was isolated, purified, synthesized cDNA, and 
qualified the gene expression by q-PCR. E. Schematic model indicates that three variants of LINC00238 contain the target region of miR-522. F. Complementary pairing and corresponding mutation between the sequences of miR-522 and LINC00238. G. LINC00238 wild or mutant type PGL3-control plasmids were transfected into HEK293T cells together with miR-522 mimic or NC. Firefly fluorescence intensity (FL) normalized by Renilla fluorescence (RL) intensity was calculated after $24 \mathrm{~h}$ transfection. H. Western blotting detected the alterations of two known miR-522 targets, SFRP2 and DKK1, expression in overexpression and depletion of LINC00238 in cells.

A

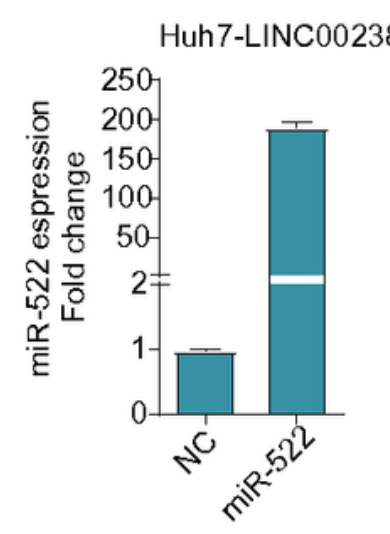

B

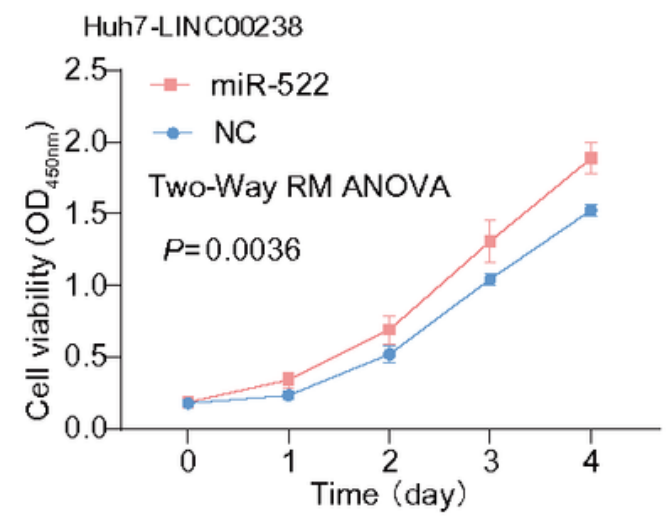

C

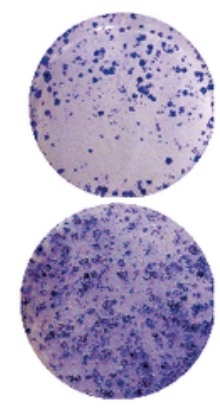

Huh7-LINC00238

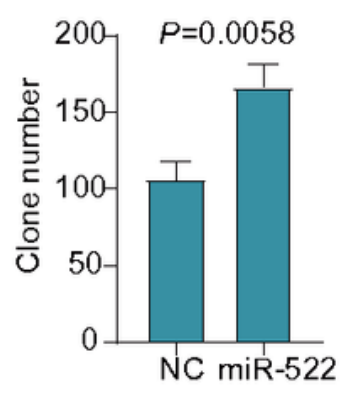

D

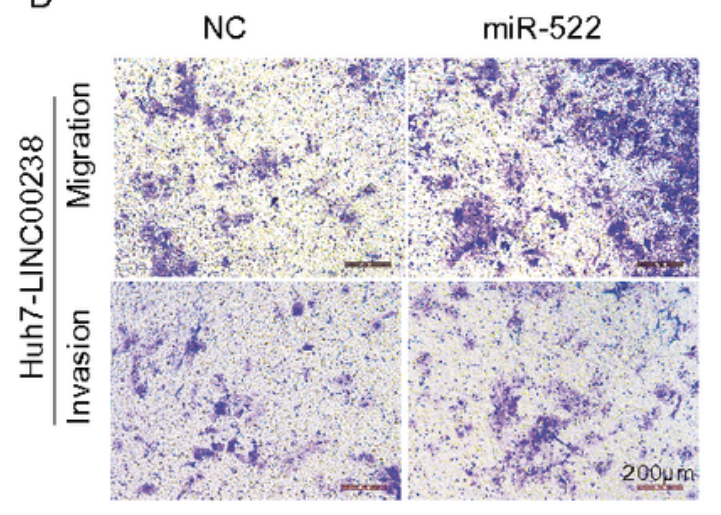

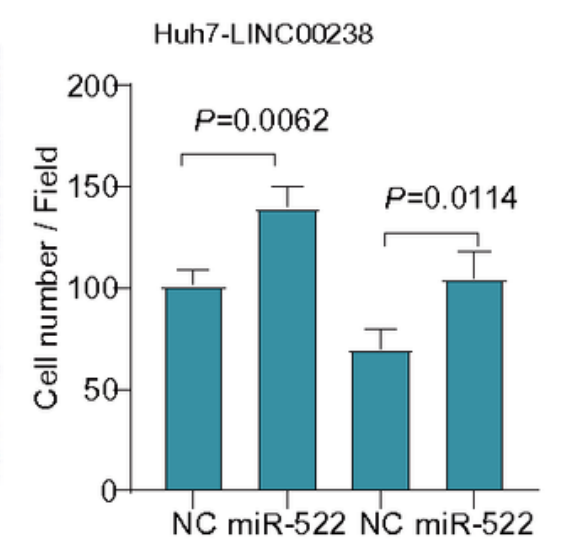

E

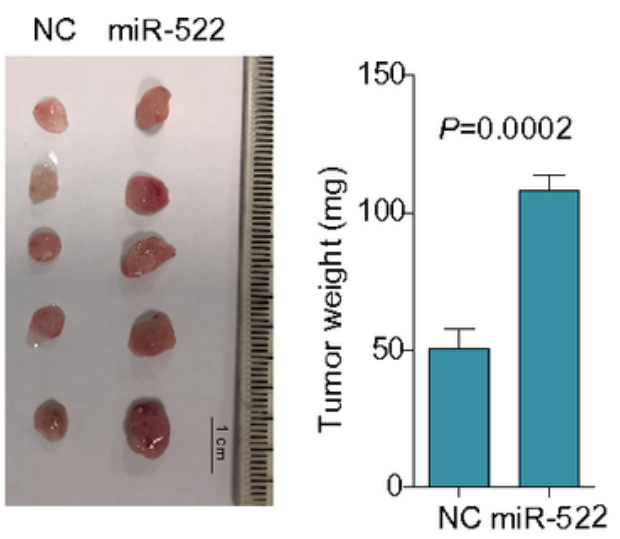

\section{F}
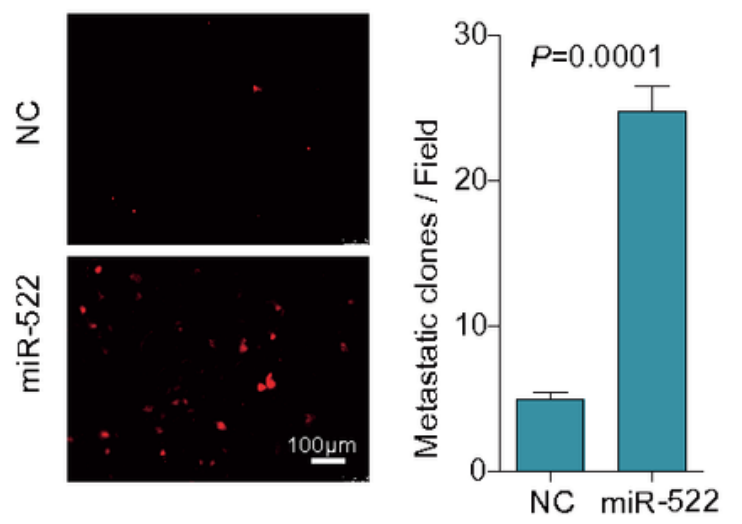

G

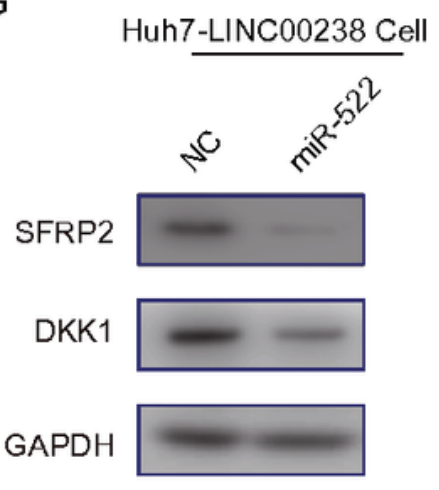




\section{Figure 6}

MiR-522 rescue expression partially diminishes the LINC00238-mediated suppression effect on malignant phenotype of HCC cell. A. LINC00238 overexpressing Huh7 cells were transfected with miR522 mimics or negative control. MiR-522 expression was detected by q-PCR. B. CCK-8 assays were performed to determine cell viability. C. Plate colony formation assays were performed to detect cell growth. D. Transwell assays were used to monitor cell migration and invasion. The number of cells was counted in four different fields. Scale bars, $200 \mu \mathrm{m}$. E. CAM assay was used to determine the effect on HCC tumor growth based on the tumor weight of each group. F. Representative pictures of lung metastasis (red fluorescent dye) taken by a laser scanning confocal microscope. The effect on lung metastasis was evaluated by the number of metastatic clones. G. Western blotting detected the SFRP2 and DKK1 expression alternation in negative control and miR-522 rescue Huh7-LINC00238 cells. 


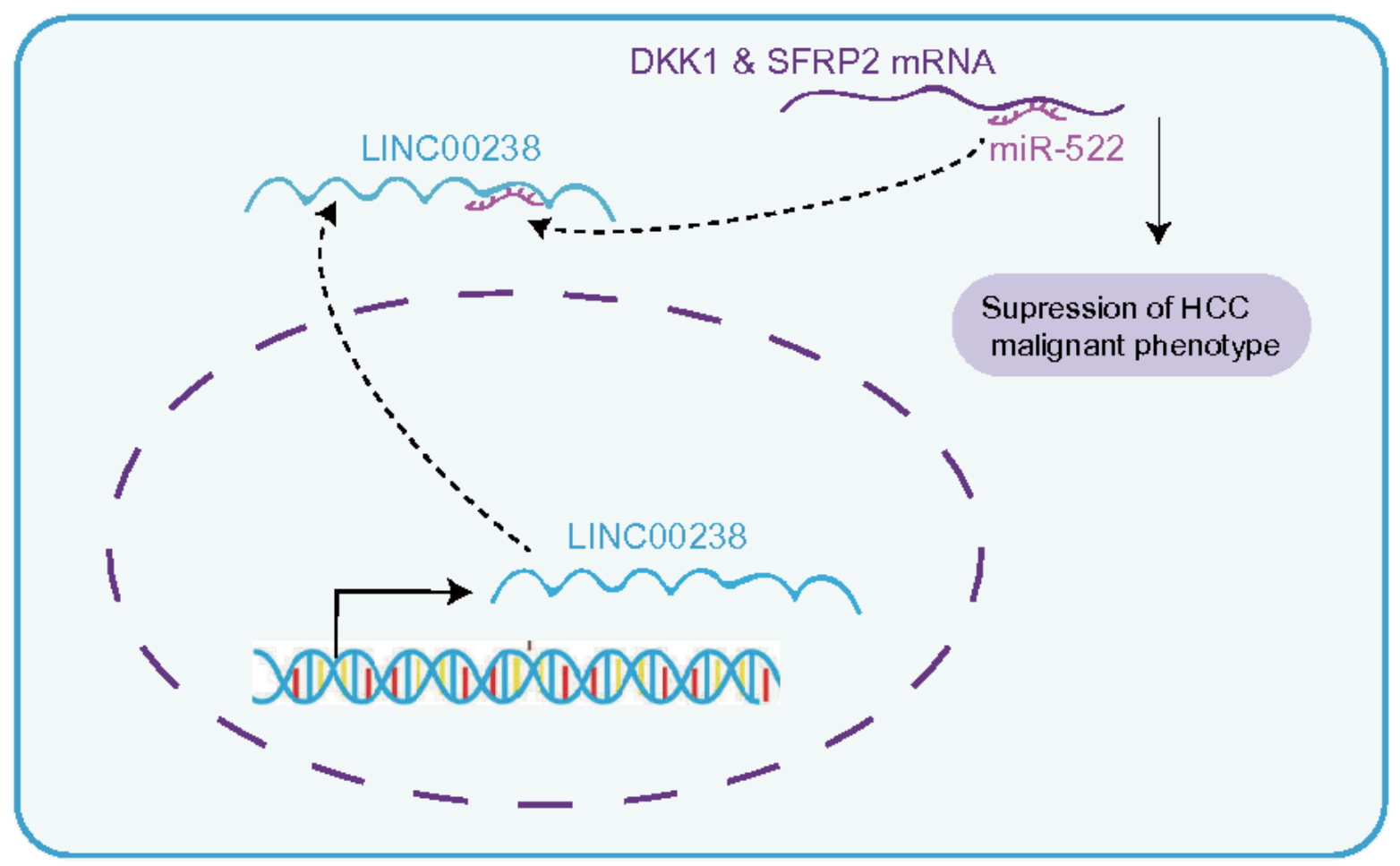

\section{Figure 7}

Schematic model for mechanism of LINC00238. LINC00238 functions as tumor suppressor by sponging miR-522, thereby relieving its repressive effect on two known miR-522 targets, SFRP2 and DKK1.

\section{Supplementary Files}


This is a list of supplementary files associated with this preprint. Click to download.

- Additionalfile1.docx

- Originalblotimages.docx 